\title{
FUNDAMENTOS PRAGMÁTICOS DE UN NUEVO MODELO DE RACIONALIDAD PRÁCTICA
}

Juan Antonio Valor*

RESUMEN: El autor plantea los supuestos ontológicos de la nueva izquierda, que componen su identidad: la realidad es múltiple y cambiante; el yo se agota en la actividad adaptativa que desarrolla en su entorno. Se asume el falibilismo y el relativismo: aparece un proyecto político nuevo.

PALABRAS CLAVE: identidad, yo, adaptación, falibilismo, relativismo, política.
ABSTRACT: The author describes the New Left's ontological assumptions that constitute its identity: reality is various and changing; the "ego" is exhausted by the adaptive activities in his environment. Fallibility and relativity are also included and thus a new political project emerges.

KEYWORDS: identity, ego, adaptation, fallibility, relativism, politics. 


\section{FUNDAMENTOS PRAGMÁTICOS DE UN NUEVO MODELO DE RACIONALIDAD PRÁCTICA}

\section{Introducción}

Llama la atención el tremendo distanciamiento que durante los últimos años se ha producido en Europa, y de manera singular en España, entre la derecha y la izquierda. La brecha que tradicionalmente las ha separado tiene ahora una profundidad mayor que la de los años ochenta y noventa del siglo pasado. A mi modo de ver, esto ha ocurrido porque una nueva izquierda está introduciendo en la sociedad planteamientos políticos y filosóficos distintos de los mantenidos por la izquierda tradicional y difícilmente conciliables con los que propone la derecha.

La derecha considera que la acción política debe respetar determinadas obligaciones morales, puntos de partida que dependen en último extremo de algo tan inalterable como la naturaleza del hombre, de la familia, de la sociedad, del derecho, del Estado, etc. Esta dependencia permite mantener las obligaciones morales sin modificación alguna, mientras el hombre siga siendo hombre, la sociedad sociedad y el Estado Estado. Por eso la derecha dice que en la política hay determinadas líneas rojas que no se pueden sobrepasar y reglas de juego que son de sentido común.

La nueva izquierda, en cambio, no cree que haya obligaciones morales inalterables, ni tampoco que exista la "naturaleza humana", o la "naturaleza de la sociedad", o la "naturaleza del Estado", sino sencillamente ciuda- 
danos concretos desenvolviéndose en el entorno complejo en el que les ha tocado vivir. Tampoco cree que el sentido común sea algo distinto de los hábitos y costumbres que defienden aquellos a los que les va bien en la vida.

La izquierda prefiere no hablar de cosas inalterables, definitivas, universales, prefiere no hablar de esencias, ni de la realidad misma, ni de lo absolutamente verdadero, ni de ámbitos transcendentales. Ha heredado de la izquierda tradicional una actitud de sospecha que lleva a pensar que todas esas palabras tejen el discurso de los poderosos. La izquierda se siente mejor cuando habla de los problemas concretos de los ciudadanos. Defiende determinadas obligaciones, pero no porque sean racionales, ni verdaderas, ni transcendentales, sino porque nos permiten definir caminos que creemos que nos llevarán a algo mejor. La política, por tanto, no trata de marcar líneas rojas o definir el terreno de juego, sino más bien de crear comunidades amplias en las que todas las sensibilidades se sientan reconocidas y tengan la posibilidad de desarrollar sus propios proyectos de vida.

A la derecha le resulta incomprensible que la izquierda con responsabilidades de gobierno se atreva a modificar obligaciones por cuya permanencia debiera velar, y el término "sensibilidades" le resulta poéticamente sugerente, pero políticamente vacío. Para la derecha, la izquierda aparece sin ideas claras, sin un proyecto político perfilado e incluso con un enorme déficit de conocimientos históricos, filosóficos y jurídicos. Todo lo cual está generando monstruos tales como la ley para regulación del aborto, la ley para la regulación de la eutanasia, la ley de matrimonio entre homosexuales, etc.

No creo que la nueva izquierda carezca de ideas claras o de proyecto político. Lo que ocurre es que los supuestos filosóficos sobre los que elabora su discurso son diferentes a los heredados de la modernidad, tan diferentes que para muchos resultan incomprensibles. Poner de manifiesto dichos supuestos es lo que pretendo en este trabajo.

\section{Prudencia y moralidad}

Defiendo la tesis de que, siguiendo algunas concepciones desarrolladas por el pragmatismo contemporáneo, la izquierda europea ha cambiado las nociones modernas de prudencia y moralidad, lo cual hace que la práctica política de los actuales gobiernos de izquierdas sea muy distinta de la práctica política de los gobiernos de izquierdas de los años 80 y comienzos de los 90 . 
NOTAS

Desde el punto de vista de la filosofía moderna, prudentes son aquellas obligaciones que consideramos condicionales e hipotéticas, y morales son aquellas que consideramos no condicionales y categóricas. La prudencia tiene que ver con el "hábito", la "costumbre", la "conveniencia" y la "eficiencia". La moral tiene que ver con las condiciones necesarias o $a$ priori de la realidad.

Para la nueva izquierda, la distinción entre prudencia y moralidad es una distinción de grado y no de clase. Esto significa que las obligaciones morales no son más que obligaciones prudentes consciente y deliberadamente tomadas. Una sociedad es moral sencillamente porque contiene una formulación explícita de unas formas de actuar que permite a los miembros de esa sociedad desenvolverse en un determinado entorno.

¿Cuándo se logra dicha formulación explícita? Cuando los usos y costumbres hasta el momento vigentes se vuelven problemáticos, cuando dejan de cubrirse las necesidades de los individuos, cuando no hay un buen ajuste al medio. En este caso se tienen que proponer nuevas formas de actuar. De entre todas ellas, calificaremos como prudentes aquellas que finalmente permitan un buen ajuste. Y serán morales en la medida en que se trata de propuestas conscientemente aceptadas frente a otras. Si con ellas se consigue un ajuste sostenido en el tiempo, entonces llegarán a ser hábitos de actuación y costumbres adquiridas, e incluso puede ocurrir que se conviertan en formas de actuar que los individuos ejecuten naturalmente. En tal momento, se habrá perdido la conciencia explícita y las que una vez fueron obligaciones morales se habrán convertido meramente en obligaciones prudenciales.

¿Por qué los usos y costumbres hasta ahora vigentes se vuelven problemáticos? La respuesta es: porque cambia el entorno, y aquellas pautas de actuación que antes generaban un buen acomodo ahora pueden generar problemas, incomodidades o inadecuaciones plenamente vividas por los individuos. Un supuesto ontológico que admite la nueva izquierda es que el entorno es múltiple y cambiante.

El fenómeno de la obligación moral es entendido desde este punto de vista como un sentimiento de novedad, que aparece cuando actuamos atendiendo a unas pautas que todavía no hemos puesto a prueba, es decir, de las que no conocemos las posibilidades de ajuste y acomodo. Que la prudencia es medrosa y la moral es heroica quiere decir sencillamente: las obligaciones prudenciales están consolidadas porque las acompaña una historia de consecuencias que generan un buen ajuste, mientras que aún no conocemos las consecuencias gene- 
radas por las obligaciones morales y, por tanto, orientan nuestra conducta sin experiencia previa. ${ }^{1}$

\section{Supuestos ontológicos de la modernidad}

Los cambios del entorno obligan a un nuevo proceso de ajuste sobre la propuesta de nuevas formas de actuación. Tanto las obligaciones prudenciales como las obligaciones morales son, por consiguiente, condicionales e hipotéticas en origen. ¿Por qué razón, entonces, se ha podido afirmar en algunos momentos de la historia del pensamiento que el ámbito de la moral contiene obligaciones no condicionales y categóricas?

$\mathrm{El}$ argumento de R. Rorty es que esta concepción de la moral se levanta sobre el inaceptable supuesto ontológico de que el yo es no relacional. ${ }^{2}$ Esto quiere decir que el yo ha sido considerado como una unidad de contornos distinguibles compuesta de, al menos, dos partes: una parte privada que lo individualiza, que hace de cada yo precisamente éste y no otro -esto es la pasión-, y otra parte que no es privada, sino que es lo que tienen en común cada uno de los yoes entre sí-estamos hablando de la razón,

${ }^{1}$ Richard Rorty, ¿Esperanza o conocimiento? Una introdución al pragmatismo, 1997, Bs.As., FCE, p. 84 .

${ }^{2}$ Ibidem. ya sea considerada desde un punto de vista óntico o desde un punto de vista ontológico-. Sobre esta división, con el término prudencia se hace referencia al conjunto de actuaciones que convienen a la pasión, y con el término moralidad se hace referencia al conjunto de actuaciones que convienen a la razón. Así las cosas, la actuación prudente, en la medida en que está referida a un yo concreto y mutable, esto es, contingente, sólo puede ser considerada como condicional, hipotética y autointeresada; por el contrario, la actuación moral no responde al interés privativo de cada cual, sino a lo que cada uno tiene de universal y necesario, por lo que es considerada como no condicional y categórica.

\section{Progreso moral y educación}

Tanto la moral como la prudencia han quedado vinculadas al proceso de ajuste de los individuos al entorno en el que se desenvuelven. Hemos considerado que se trata de un entorno múltiple y cambiante. ¿Tiene sentido, en tal caso, hablar de progreso moral, o más bien debiéramos afirmar la fragmentación del ámbito de lo moral e incluso la inconmensurabilidad de las partes resultantes?

La nueva izquierda defiende la idea de un progreso moral entendido 
NOTAS

no como un aumento de la racionalidad, sino como un aumento de la sensibilidad. Y al explicar lo que esto significa, la izquierda dice cosas tales como "un aumento de la capacidad para responder a las necesidades de una variedad más y más extensa de personas y de cosas"; " "expandir la referencia de expresiones personas de nuestro tipo y gente como nosotros"; 4 "creciente capacidad de ver las similitudes entre nosotros y los que son muy diferentes a nosotros como si sobrepujaran a las diferencias". ${ }^{5}$

La educación moral no puede vincularse, en tal caso, a un desarrollo de la capacidad de conocer lo que más conviene a la razón, sino que queda vinculada a la educación sentimental, es decir, al pleno desarrollo de la variedad, la libertad y el enriquecimiento humano. Pero estas expresiones sólo tienen sentido cuando nos entendemos a nosotros mismos como yoes relacionales que tratamos de desenvolvernos en un determinado entorno. Tratemos de explicar qué significa esto.

\section{Análisis del yo relacional}

La concepción del yo relacional la defiende R. Rorty en los artículos

${ }^{3}$ Rorty, op. cit., p. 91.

${ }^{4}$ Richard Rorty, Verdad y progreso. Escritos filosóficos 3, 2000, Barcelona, Paidós, p. 230. ${ }^{5}$ Ibid., p. 236. titulados "Daniel Dennett en torno a la intrinsicidad" $\mathrm{y}$ "Un mundo sin sustancias o esencias".?

La hace depender de lo que llama nominalismo psicológico. Esta doctrina afirma que: 1) no hay nada que conocer acerca de los objetos más que sus relaciones en toda dirección con otros objetos; 2) estas relaciones se componen y se entretejen en una determinada descripción; 3) no hay una descripción privilegiada del objeto real porque no hay objeto real independientemente de la descripción; $y$, 4) hay descripciones mejores que otras en la medida en que unas logran un propósito humano mejor que otras. ${ }^{8}$

Otra manera de decir lo mismo es afirmar que los objetos son centros de gravedad descriptiva, término que usa Daniel Dennett en su conocida obra La conciencia explicada. ${ }^{9}$ Los objetos están tejidos y entretejidos en el seno de una determinada descripción que puede tener, por ejemplo, la forma de una narración. A medida que cambia la narración cambian los objetos, es decir, los centros de gravedad descriptiva se desplazan. Y no se trata en ningún momento de captar sus propiedades intrínsecas, porque más allá o más debajo de la superficie relacional en la que se muestran no hay nada. Desde este punto

${ }^{6}$ Ibid., pp. 133-65.

${ }^{7}$ Rorty, ¿Esperanza o conocimiento?, op. cit., pp. 43-76.

${ }^{8}$ Ibid., p. 53.

${ }^{9}$ Rorty, Verdad y progreso, op. cit., p. 142. 
de vista, tan poca hondura tienen los números, las mesas, los quarks, las estrellas o los valores morales como los calcetines extraviados de Daniel Dennett.

Y la misma tesis se puede afirmar acerca del yo, de la persona o de la autoidentidad, dado que no es más que un objeto entre los objetos. No existe "un verdadero yo, un yo en soi que me corresponda captar". ${ }^{10}$ No tiene sentido, en tal caso, plantear la existencia de una razón universal única y estable común a todos los yoes $\mathrm{y}$, consecuentemente, no se pueden entender las obligaciones morales como maneras de actuación que, por convenir a esa razón, han de ser consideradas como no condicionales y categóricas.

Lo que hay es un yo sin ninguna pretensión de transcendencia, un yo que se agota en las relaciones que mantiene con el resto de los objetos -y hay que estudiar los tipos de relaciones, porque no todas son de la misma índole-. R. Rorty lo define, al hilo de la lectura de un poema de Philip Larkin, como un yo de contingencias particulares que componen una vida individual en la que no se encuentra ningún rastro de alguna marca definitiva que se pueda aplicar a todos los hombres. ${ }^{11}$ Un yo, en definitiva, múltiple y cambiante, al que sólo le

${ }^{10}$ Ibidem .

${ }^{11}$ Richard Rorty, Contingencia, ironía y solidaridad, 1991, Barcelona, Paidós, pp.43-7. puede convenir, en función de su ajuste a un entorno también múltiple y cambiante, maneras de actuar condicionales e hipotéticas.

\section{Análisis del proceso de ajuste al entorno}

Al hablar de ajuste al entorno, el pragmatismo propone que nos entendamos a nosotros mismos como organismos que continuamente estamos lidiando con el entorno, tratando de acomodarnos a él mediante ciertas pautas de comportamiento que pueden ser más o menos efectivas. Desde este punto de vista, la diferencia entre una ameba y Einstein no es cualitativa, sino cuantitativa; ambos desarrollan el tipo de conducta que les permite acomodarse al mundo en el que viven.

El proceso de ajuste al entorno sigue un esquema sencillo: el organismo se siente irritado en el medio en el que vive y busca una respuesta conductual que le permita apaciguar la irritación. Si este objetivo se logra, diremos que la respuesta conductual es adecuada, o bien que ha habido un buen ajuste al entorno.

Esto sitúa al organismo en condiciones de comportarse de determinada manera dadas determinadas condiciones del entorno. O dicho de otro modo: se ha generado en él un hábito de acción. En definitiva, al hablar de ajuste al entorno nos referimos al 
NOTAS

comportamiento más o menos complejo tendente a cubrir las necesidades de los organismos en el entorno que habitan. El sentimiento de irritación es el signo que da noticia de una necesidad vivida, y el sentimiento de tranquilidad y satisfacción es el signo que da noticia de un buen acomodo al entorno. Si mediante un determinado comportamiento este acomodo se logra, entonces el organismo adquiere un hábito que orientará su actuación en el futuro bajo las mismas o parecidas circunstancias. La creencia indica que el hábito ha sido efectivamente adquirido.

Ahora se entiende mejor la noción de prudencia que maneja la nueva izquierda. Tiene que ver con este modo de lidiar con el entorno buscando un ajuste que permita aplacar la irritación vivida en primera persona por el individuo. Dado que el entorno es múltiple y cambiante, nuestra experiencia es la de estar continuamente arreglándonoslas con lo accidental. Puesto que ni en el entorno ni en el yo encontramos rastro de alguna marca definitiva, universal y necesaria, no es posible argumentar a favor de la moralidad entendida como un conjunto de obligaciones no condicionales y categóricas. Por el contrario, sólo se puede argumentar a favor de aquel repertorio de obligaciones contingentes que permite a los individuos acomodarse al entorno concretísimo en el que se están desenvolviendo.

\section{Defensa del falibilismo}

Si lo que se pretende es encontrar un ajuste, ¿cómo sabemos de antemano qué conducta hemos de desarrollar? La respuesta es que de antemano no lo sabemos. Es necesario experimentar, es decir, comprobar que efectivamente la ejecución de una determinada conducta permite eliminar la irritación y recuperar la tranquilidad y satisfacción perdidas. Por consiguiente, las soluciones que se proponen son, de antemano, meramente tentativas; se trata de propuestas arriesgadas que pueden tener éxito adaptativo o no. Y porque lo que parecían luminosas soluciones pueden convertirse, a la luz de la experiencia, en rotundos fracasos, la nueva izquierda no puede creer en la revolución, sino en la reforma continua.

En definitiva, se trata de afirmar que las creencias sólo se justifican mediante sus consecuencias, o dicho de otro modo, por la diferencia que implican en lo existente.

Y si somos falibilistas, entonces entenderemos que, dada una irritación, cuantos más discursos haya, mejor, porque más oportunidades tendremos de aplacarla y conseguir el deseado ajuste al entorno. Por esta razón insiste la nueva izquierda en que uno de los bienes más relevantes que deben preservar las sociedades occidentales democráticas, capitalistas y burguesas, es la variedad disponible. 
Los discursos que se lanzan son denominados memes, término que emplea R. Rorty y atribuye a Richard Dworkin y Daniel Dennett. Los memes asumen, desde una perspectiva cultural, el papel de los genes de Mendel. Son cosas como giros del lenguaje, expresiones de encomio moral o estético, lemas políticos, refranes, frases musicales, iconos estereotipados y similares.

Ejemplos de memes que han tenido éxito adaptativo son El Nuevo Testamento, la Ilustración, los Principia Mathematica, La Fundamentación de la metafisica de las costumbres, el Ingenioso Hidalgo don Quijote de la Mancha o el feminismo contemporáneo. En estos casos, no nos encontramos con teorías que ofrecen una nítida explicitación de la realidad, sino sencillamente con propuestas que buscan solución a problemas vividos en un determinado entorno histórico y cultural. Si alguna vez creímos en ellas, no es porque nos revelaron la verdad, sino sencillamente porque nos dieron cobijo y nos proporcionaron acomodo.

\section{La educación sentimental}

La adopción del falibilismo en el mundo moral obliga, en primer lugar, a rechazar la idea de lo intrínsecamente bueno y lo intrínsecamente malo. Decía J. Dewey que hasta el momento de su deliberación y antes de su elección, lo malo es un bien en competencia con otros en el espacio cultural disponible. El mal o lo peor es sencillamente un bien rechazado una vez evaluadas sus consecuencias en un entorno cambiante, y lo bueno no es más que aquello que se predica de las obligaciones que generan consecuencias adaptativas para los individuos. Dado que el entorno es cambiante, la experimentación debe ser continua también en el ámbito de lo moral. Y por ello las obligaciones morales sólo pueden ser consideradas como obligaciones prudenciales, es decir, condicionales e hipotéticas.

En segundo lugar, el falibilismo obliga a defender la existencia de una amplia variedad de discursos disponibles, cuantos más, mejor. La razón es que la mutabilidad del entorno puede hacer que el discurso hasta el momento adaptativo se convierta, en el nuevo entorno, en una fuente de irritaciones y de problemas vividos plenamente por los individuos. En tal caso, nos veremos obligados a experimentar con otros discursos guiados siempre por un criterio, que es la eliminación de la irritación y la búsqueda del ajuste al entorno. Y en el momento de la experimentación los discursos disponibles representan buenas oportunidades de conseguir el ajuste deseado.

La nueva izquierda vincula la educación sentimental al desarrollo 
NOTAS

de la capacidad de tomarse en serio y respetar todos los discursos disponibles en la medida en que constituyen un buen banco de posibilidades adaptativas para el futuro, aunque en un determinado momento algunos de ellos sean minoritarios y poco relevantes. La educación sentimental, la variedad y la libertad, están relacionadas cuando los distintos discursos disponibles se entienden como buenas oportunidades para liberar a los hombres de la irritación y el dolor padecidos en su entorno.

Así las cosas, carece de sentido concebir el progreso moral como un aumento de la racionalidad; hay que concebirlo como un aumento de la sensibilidad, es decir, de la capacidad para responder a las necesidades sentidas por una variedad cada vez más extensa de personas y cosas. Se puede hablar de un futuro humano mejor, e incluso se puede evaluar; diremos que es mejor cuando contiene más de lo que consideramos bueno y menos de lo que consideramos malo. ¿Y qué es lo que la nueva izquierda considera bueno? La respuesta es clara: la variedad y la libertad. ${ }^{12}$

\section{Pragmatismo y darwinismo}

Hasta aquí he pretendido dar cuenta de que el discurso de la nueva izquierpp. 13-5.

${ }^{12}$ Rorty, ¿Esperanza o conocimiento?,op. cit., da depende de tres tesis ontológicas. La primera tesis dice que el entorno no es uno y esencialmente inmutable, sino que, por el contrario, es múltiple y cambiante. La segunda tesis dice que eso a lo que llamamos yo no es una unidad esencialmente distinta de los objetos con los que trata, sino que, por el contrario, el yo se agota en las relaciones que mantiene con dichos objetos. La tercera tesis dice que la acción del individuo en el entorno está orientada por la eliminación de la irritación vivida y por la búsqueda de un ajuste.

Estas tesis se han formulado haciendo un uso explícito y reiterado del darwinismo. Desde el darwinismo es rechazado, en primer lugar, cualquier tipo de fijismo ontológico; en segundo lugar, la distinción entre yo y objetos se sustituye por la categoría de acción de un organismo en el entorno; en tercer lugar, se considera que dicha actividad es adaptativa.

La pregunta que me hago es cómo hay que entender este darwinismo, tan característico de la tradición pragmatista y de la nueva izquierda.

Podemos considerar que la teoría darwinista es filosofía primera, es decir, la explicación originariamente verdadera y definitiva de lo real. Desde este punto de vista, Darwin sería el descubridor de la auténtica realidad oculta, y todos los demás nos veríamos obligados a esclarecer cuestiones en uno u otro ámbito siempre justificadas en la explicación originaria. Si 
NOTAS

ésta fuera la concepción de la nueva izquierda, entonces todo su pensamiento dependería de un biologicismo injustificado, el cual no es compatible con los supuestos ontológicos que defiende.

La respuesta es que el darwinismo es un relato. Es un relato sobre seres humanos y animales con órganos y capacidades específicas, las cuales permiten definir quiénes somos y qué queremos. Es un relato que genera una determinada imagen, que es la de los-humanos-como-animales-ligeramente-más-complicados en una relación estrictamente causal y no representacionista con el resto del universo. ${ }^{13}$

Como todo relato, puede ser útil o no, y se aceptará en función de su utilidad. La utilidad se evalúa atendiendo a las consecuencias prácticas que genera, es decir, a la capacidad que tiene de ajustar aproblemáticamente a los individuos en el entorno en el que se desenvuelven. En concreto, el darwinismo es una redescripción más útil porque elimina los problemas filosóficos tradicionales (los elimina no porque los soluciona, sino porque hace imposible su formulación) al tiempo que ofrece una imagen naturalizada del hombre que permite lidiar con los problemas que surgen en la realidad actualmente vivida. ${ }^{14}$

\footnotetext{
${ }^{13}$ Rorty, Verdad y progreso, op. cit., pp. 69-70.

${ }^{14}$ Rorty, ¿Esperanza o conocimiento?, op. cit., pp. 71-6.
}

\section{Pragmatismo y relativismo}

Se puede ser darwinista y realista a la vez si se mantiene el supuesto ontológico de que hay una unidad de lo real más allá de la mutabilidad del entorno y la adaptación de los organismos. En este caso, la teoría de Darwin no sería la explicación más profunda, sino que se podría deducir de otra teoría, en último extremo física, que explicase la mutabilidad del entorno y la adaptación desde la unidad originaria.

El darwinismo sólo conduce al relativismo cuando se completa con la tesis de que la realidad es múltiple y cambiante. Así, la teoría de Darwin sí daría una imagen definitiva para la investigación, a saber, la de una realidad constituida por distintas regiones y una multitud de organismos adaptándose mediante distintas prácticas. Puesto que la validez de dichas prácticas depende de su utilidad adaptativa al entorno y contamos, como punto de partida, con distintos entornos, entonces resulta que pueden coexistir distintas prácticas y todas ellas válidas.

Si las diferentes regiones de la realidad junto con sus organismos configurasen nichos ecológicos absolutamente impermeables, sin relación alguna entre ellos, y nichos absolutamente estables, sin cambios a lo largo del tiempo, entonces las prácticas que proporcionan éxitos adaptativos 
NOTAS

serían definitivamente válidas. Pero la experiencia de la vida cotidiana muestra que esto no es así. Por un lado, hay relación entre unas regiones y otras y entre unos organismos y otros; por otro lado, las regiones son cambiantes, y en ellas no encontramos rastro alguno de estabilidad. Todo ello genera continuamente nuevos problemas, nuevas irritaciones que los organismos necesitan aplacar. Y esto sólo se puede conseguir mediante nuevas prácticas, porque el uso reiterado de las antiguas genera, a partir de determinado momento, más problemas.

La validez de las prácticas depende de su capacidad para conseguir individuos adaptados al medio; esto es relativismo. Pero el relativismo no tiene que ver con la arbitrariedad, porque las nuevas prácticas que se proponen son consideradas como buenas en la medida en que efectivamente logran aplacar la irritación vivida. Hay aquí un rasgo de objetividad que, a mi modo de ver, hay que atribuir al modelo de la nueva izquierda, aunque frecuentemente no se le concede la relevancia debida.

Rorty se refiere a ello, por ejemplo, en "La verdad sin correspondencia". ${ }^{15}$ Defiende que el conocimiento consiste en justificar las creencias ante una audiencia, y "ninguna audiencia está más próxima a la naturaleza ni es mejor representante que cualquier otra de algún ideal ahistórico de la

\footnotetext{
${ }^{15}$ Ibid., pp. 7-42.
}

racionalidad", ${ }^{16}$ pero con anterioridad ha dejado claro, recurriendo a Davidson, "que nunca podemos ser más arbitrarios de lo que el mundo nos permite ser". ${ }^{17}$ En el artículo titulado "Feminismo y pragmatismo", ${ }^{18}$ Rorty destaca el dolor como rasgo que permite defender la objetividad y la intersubjetividad. Argumenta en contra de la existencia de rasgos intrínsecos al ser humano sobre los cuales justificar los derechos humanos, y concluye que "si 'intrínseco' significa 'ahistórico, no tocado por el cambio histórico', entonces los únicos rasgos intrínsecos de los seres humanos son aquéllos que comparten con los brutos: por ejemplo, la capacidad de sufrir y de infligir dolor". ${ }^{19}$ El dolor no está caracterizado aquí como algo meramente subjetivo o psicológico, sino como una situación vivida problemáticamente por individuos a los que se les impone un determinado entorno en función de usos y costumbres heredados.

La susceptibilidad compartida al dolor y a la humillación es el rasgo objetivo que permite la resolución de conflictos. El conflicto surge cuando hay una relación entre grupos de individuos con diferentes formas de actuación. Confundimos el relativismo con la arbitrariedad si afirmamos que la resolución del conflicto consis-

\footnotetext{
${ }^{16}$ Ibid., p. 32.

${ }^{17} \mathrm{Ibid}$., pp. 25-6.

${ }^{18}$ Rorty, Verdad y progreso, op. cit., pp. 243-75.

${ }^{19}$ Ibid., p. 247.
} 
te en una mera lucha de poder. Al pragmatismo se le acusa con frecuencia de reducir el desacuerdo moral a una mera lucha de poder, dado que prescinde de los clásicos tribunales neutrales, como son la razón o la naturaleza humana. Pero la sustancia del argumento de Rorty en contra de esta opinión es que pasa por alto que las obligaciones morales que tienen éxito son aquellas que consiguen el ajuste de los individuos a un entorno que se impone, no en sí mismo, sino en función de las prácticas de los individuos..$^{20}$ De tal forma que la erradicación del dolor y la humillación vividos por unos individuos y por otros en el entorno problemático en el que se relacionan es el criterio no arbitrario, sino absolutamente objetivo, que permite resolver el conflicto en el seno de nuevas prácticas compartidas, las cuales generan, al tiempo, un nuevo entorno. En "Habermas, Derrida y las funciones de la filosofía" 21 insiste Rorty en que La cabaña del Tío Tom, Los miserables, La granja africana, Sin novedad en el frente, El pozo de la soledad, People of the Abyss, Black Boy, Rebelión en la granja, e innumerables artículos de periódicos, informes, etc., han hecho más por la filosofía que la "validez universal" habermasiana..$^{22}$ La razón es que han puesto de relieve el dolor vivido por

${ }^{20}$ Ibid., pp. 254-6.

${ }^{21}$ Ibid., pp. 341-65.

${ }^{22}$ Ibid., pp. 357-61. los hombres en una determinada situación y han aportado nuevos discursos repletos de nuevas prácticas destinadas a situar a los hombres en un entorno en el que no aparezcan aquellas situaciones dolorosas.

\section{Conclusión}

Por consiguiente, entiendo que el supuesto más importante sobre el que se levanta el discurso político de la nueva izquierda es la identidad entre prudencia y moralidad. Dicha identidad se fundamenta a su vez en tres supuestos ontológicos: el primero dice que la realidad es múltiple y cambiante; el segundo y el tercero los podemos reformular diciendo que el yo se agota en la actividad adaptativa que desarrolla en su entorno. Puestas las cosas así se comprende que la nueva izquierda asuma el falibilismo y el relativismo, pero he querido destacar que ello no conduce al escepticismo. Hoy la izquierda puede seguir defendiendo criterios de validez sobre los cuales orientar su acción de gobierno. La diferencia con la izquierda moderna e ilustrada de ayer y con la derecha de siempre es que esos criterios no tienen que ver con apriorismos de la razón, sino con algo más pequeño y también más humano, a saber, con la capacidad de sentir el dolor, el límite, la negación. 
La reproducción total o parcial de este artículo se podrá hacer si el ITAM otorga la autorización previamente por escrito. 